\title{
Cyclic Voltammetric Studies of Electropolymerized Films Based on Ruthenium(II/III) Bis(1,10 phenanthroline) (4-methyl-4'vinyl-2,2'-bipyridine)
}

\author{
Kenneth L. Brown (Corresponding author) \& Seth B. Gray \\ Department of Chemistry, Hope College \\ 35 East $12^{\text {th }}$ Street, Holland, Michigan 49424, USA \\ Tel: 1-616-395-7173Ｅ-mail: brownk@hope.edu
}

\begin{abstract}
A ruthenium complex of bis(1,10-phenanthroline)(4-methyl-4'vinyl-2,2'-bipyridine) was used to modify glassy carbon electrodes during cyclic voltammetry. The modification procedure is rapid and produces a polymer film on the glassy carbon electrode. Characterization cyclic voltammograms of the ruthenium-based polymer films in supporting electrolyte solutions are very similar to the electropolymerization cyclic voltammograms. The polymer thin films derived from the ruthenium complex exhibit Nernstian electron transfer with respect to the applied potential at low scan rates. This is shown by the small peak separation between the cathodic and anodic peaks during characterization. At scan rates greater than $1.00 \mathrm{~V} / \mathrm{sec}$, the films model the Randles-Sevcik equation for diffusion-controlled mass transfer processes. Surface coverage ranges from $9.42 \times 10^{-11} \mathrm{~mol} / \mathrm{cm}^{2}$ to $4.76 \times 10^{-10} \mathrm{~mol} / \mathrm{cm}^{2}$ and was calculated by integrating the area under the anodic peak of the characterization cyclic voltammograms.
\end{abstract}

Keywords: Electropolymerization, Cyclic voltammetry, Thin films

\section{Introduction}

Chemically modified electrodes (CMEs) over the past several decades have sparked considerable interest in analytical chemistry with respect to catalysis, electrochemical and chromo-electrochemical detection of organic compounds, and chemical sensor development. Since the pioneering work by Lane and Hubbard, over 20 years ago, involving chemisorbed metals on platinum electrode surfaces, numerous methods have been developed to immobilize compounds on electrode surfaces (Lane 1973). Several modification techniques of electrode surfaces include covalent attachment, spin coating, and electropolymerization. This research focuses on polymer films on glassy carbon electrode derived from electropolymerization.

Deliberate chemical alteration of the electrode surface may result in a more favorable interaction between an analyte and electrode surface by changing the thermodynamic and kinetic behavior of reactants, products, or intermediates involved in the redox transformation. These new electrodes possess properties which may be exploited to lay a foundation for new and interesting applications and devices such as electrochromic displays and sensors (Green et. al 1983, Hurrell et. al 1989, Li et. al 1991, Wang 1996, Allen et. al 1994, Bobacka et. al 1994). Electropolymerization offers a unique strategy of reproducibly immobilizing metal complexes with various degrees of electrochemical activity onto electrode surfaces (Brown et. al 1998, Brown et. al 2002). Research in the development of chemically modified electrodes by electrochemical polymerization using $\mathrm{Ru}(\mathrm{II})$ and $\mathrm{Fe}(\mathrm{II})$ vinylbipyridine complexes was performed by Calvert (Calvert et al. 1983). Others such as Guarr et al. have investigated the mechanism of electropolymerization for ruthenium bis(1,10-phenanthroline)(4-methyl-4'vinyl-2,2'-bipyridine), Ru(II)-(phen) $)_{2}$ vbpy (where vbpy=vinyl bipyridine), complexes onto glassy carbon electrode surfaces (Guarr et. al 1987). The electrodes presented herein require approximately 30 minutes to modify depending upon the scan rate used for electropolymerization.

More recently, we investigated the use of electrodes chemically modified with $\mathrm{Ru}$ (II)-5-amino-1,10-phenanthroline-bis(bipyridine) complexes towards the electrochemical oxidation detection of hydrazine at significantly lowered overpotentials (Pinter et. al 2007). These films were based on the oxidation of the amine group of the organic moiety. Planning the incorporation of immobilized ruthenium complexes for the design of amperometric sensors for hydrazine, we have revisited the electropolymerization of a ruthenium compound containing mixed ligands of vinylbypyridine and phenanthroline. The films derived from these mixed ligands were electrochemically characterized using cyclic voltammetry. The characterization data would provide 
useful information related to the design of sensors for hydrazine. This paper reports on some of the electrochemical characteristics of the ruthenium-based films on glassy carbon electrode surfaces.

\section{Experimental}

\subsection{Reagents and Solutions}

The ruthenium complex, $\mathrm{Ru}(\mathrm{II})-(\mathrm{phen})_{2} \mathrm{vbpy}$, was provided by Guarr and co-workers. Propylene carbonate and tetraethlyammonium perchlorate (TEAP), used as solvent and supporting electrolyte for electropolymerization of the monomer and characterization of the films were obtained from Sigma-Aldrich (St. Louis, MO). The TEAP was dried under vacuum prior to use. The concentration of monomer and TEAP were $1.00 \times 10^{-3} \mathrm{M}$ and $0.100 \mathrm{M}$ respectively.

\subsection{Instrumentation}

Electropolymerizations and other cyclic voltammetric measurements were performed with a 601A Electrochemical Analyzer (CHInstruments, Inc., Austin, TX). The three-electrode electrochemical cell used in this work consisted of a glassy carbon working electrode (diameter $=3 \mathrm{~mm}$ ), a Ag/ $\mathrm{AgCl}, 3 \mathrm{M} \mathrm{NaCl}$ reference electrode, and a platinum wire auxiliary electrode, all from CHInstruments.

\subsection{Electropolymerization and Characterization of Thin Films}

Before commencing with the electrode modification with the ruthenium complex, the glassy carbon working electrode was polished by placing several drops of polishing alumina suspension $(0.05 \mu \mathrm{m}$ particle size from Bioanalytical Systems) on a wetted polishing pad and moving the electrode in a circular motion across the surface of the polishing pad. Prior to all electropolymerizations, the solutions containing the ruthenium complex and the supporting electrolyte were deoxygenated with nitrogen gas for five minutes and a nitrogen blanket was maintained over the solutions for the duration of the experiments. The electropolymerization was accomplished by cycling the potential of the glassy carbon electrode between $+1.600 \mathrm{~V}$ and $-1.600 \mathrm{~V}$. The dependence of peak current on the scan rate of electropolymerization was made using scan rates from $0.100 \mathrm{~V} / \mathrm{sec}$ to $1.000 \mathrm{~V} / \mathrm{sec}$. The maximum number of electropolymerization cycles was 90 .

The films were characterized between $+1.600 \mathrm{~V}$ and $-1.600 \mathrm{~V}$ or $-0.400 \mathrm{~V}$ vs. $\mathrm{Ag} / \mathrm{AgCl}$ in the supporting electrolyte solution of propylene carbonate with TEAP. Scan rates for characterization ranged from $0.10 \mathrm{~V} / \mathrm{sec}$ to $10 \mathrm{~V} / \mathrm{sec}$.

\section{Results and Discussion}

\subsection{Electropolymerization of Ru(II)-(phen) ${ }_{2}$ vbpy on Glassy Carbon Electrodes}

The deposition of the ruthenium complex onto glassy carbon electrodes by initiating reductive electrochemical polymerizations of the ruthenium complex was accomplished by cycling the potential applied to the glassy carbon electrode from $1.600 \mathrm{~V}$ to $-1.600 \mathrm{~V}$. This is an efficient way of producing a multi-layered polymer film and hence produce a three-dimensional network of ruthenium redox centers. Several researchers have reported values of 24-1560 monolayers based upon the packing density of the polymer films formed from Bis(vinylterpyridine)cobalt(II). These films were used in the electrochemical reduction of carbon dioxide and oxygen (Abruna et.al 1981, Hurrell et. al 1988). After completing 90 cycles of electropolymerization, three redox couples showing electrochemical reversibility persisted as shown in Figure 1. The first redox couple (Peaks 1 and 2) has a formal reduction potential, $\mathrm{E}^{\mathrm{o}}=\left(\mathrm{E}_{\mathrm{pa}}+\mathrm{E}_{\mathrm{pc}}\right) / 2$, of $1.215 \mathrm{~V}$ and is related the electrochemical activity of $\mathrm{Ru}(\mathrm{III} / \mathrm{II})$. Two other key redox couples with $\mathrm{E}^{\mathrm{o}}$, values of $-1.255 \mathrm{~V}$ (Peaks 3 and 4) and $-1.413 \mathrm{~V}$ (Peaks 5 and 6) were identified. These peaks correspond to the electrochemical activity of the ligand, vinylbipyridine (Meyer et. al 2005, Guarr et. al 1987, Calvert et.al 1983). Several research groups also identified two ligand-based redox processes of the ruthenium vinylbipyrridine complexes based upon potential scanning methods. Cathodic peak 7 (ca. $-1.150 \mathrm{~V}$ ) and anodic peak 8 (ca. $1.250 \mathrm{~V}$ ) did not appear until cycle 5, and are associated with the processes of charge trapping as the polymeric thin film forms (Guarr et. al 1987). Equations 1-3 summarize the electrochemical reactions corresponding to the reversible electrochemical processes shown in Figure 1.

$$
\begin{aligned}
& \mathrm{Ru}(\mathrm{III})-(\text { phen) })_{2} \text {, vbpy }+\mathrm{e}-\stackrel{1}{\rightleftarrows} \mathrm{Ru}(\mathrm{II})-(\text { phen })_{2} \text {, vbpy } \\
& \mathrm{Ru}(\mathrm{II})-(\text { phen) })_{2}, \text { vbpy }+\mathrm{e}-\stackrel{3}{\longleftrightarrow} \mathrm{Ru}(\mathrm{II})-(\text { phen })_{2}, \text { vbpy }{ }^{-}
\end{aligned}
$$




$$
\mathrm{Ru}(\mathrm{II})-(\text { phen })_{2} \text {, vbpy }^{-}+\mathrm{e}-\stackrel{5}{\rightleftarrows} \mathrm{Ru}(\mathrm{II})-(\text { phen) })_{2}, \mathrm{vbpy}^{2-}
$$

Diffusion controlled conditions dominate the mass transfer mechanism of the monomer to the electrode surface during electropolymerization as evidenced by linear diagnostic plots of the peak current versus the square root of the scan rate (Figure 2) provided during the third cycle of the electropolymerization (Brown et. al 2002). Peak separation for the $\mathrm{Ru}(\mathrm{III} / \mathrm{II})$ redox couple ranges from $0.071 \mathrm{~V}-0.118 \mathrm{~V}$ using scan rates of $0.100 \mathrm{~V} / \mathrm{sec}-1.00$ $\mathrm{V} / \mathrm{sec}$, and follows the trend for electrochemical systems transitioning from reversible to quasireversible electrochemistry.

The semi-conducting film containing $\mathrm{Ru}(\mathrm{III} / \mathrm{II})$ redox centers acts as a mediator at the film-solution interface to facilitate the electropolymerization process. Increases in the peak currents per cyclic voltammetric scan for electropolymerization indicates the formation and growth of the polymeric thin film on the glassy carbon electrode. After 90 cycles of electropolymerization, the peak currents approach a steady-state value. This is partly due to a reduced electrode surface area available for deposition as the number of electropolymerization cycles approaches 90, and a thicker film which causes a reduction in charge migration rate within the film. Furthermore, plots of the peak current versus the voltammetric cycle of electropolymerization are linear with a non-zero intercept which signifies a fast initial electropolymerization process that begins diffusion of the monomer to the electrode surface (Calvert et. al 1983). The mechanism for the electropolymerization of this complex and similar complexes with vinyl groups have been reported in detail and involves the formation of radical anions which react at the electrode surface and subsequent chemical reactions (Guarr et. al 1987).

\subsection{Electrochemical Behavior of Ru(II)-(phen) ${ }_{2}$, vbpy Polymer Films}

After electrochemical deposition of the ruthenium complex, the glassy carbon electrode revealed a slight orange color. Figure 3 shows the subsequent electrochemical characterization of the electrode surface in $0.10 \mathrm{M}$ TEAP in propylene carbonate at a scan rate of $0.100 \mathrm{~V} / \mathrm{sec}$ which produced the same redox couples as shown in Figure 1. The peaks related to the charge trapping process were also observed when characterizing the thin films in the same supporting electrolyte solution. Observation of the peaks in the same proximity as the peaks in the solution phase electrochemistry provides further evidence for successful immobilization of the ruthenium complex onto the glassy carbon electrode. The electrochemical observations reflect charge transfer within the polymer film between neighboring redox centers through a proposed "electron-hopping" mechanism and are related to Equations 1-3.

Characterizing the film in the supporting electrolyte solution of $0.10 \mathrm{M}$ TEAP in propylene carbonate with a circumscribed potential window from $1.600 \mathrm{~V}$ to $0.400 \mathrm{~V}$ (Figure 4) restricts the electrochemistry to involve the $\mathrm{Ru}(\mathrm{III} / \mathrm{II})$ redox couple, corresponding to Equation 1 . At scan rates higher than $1.000 \mathrm{~V} / \mathrm{sec}$, the voltammograms resemble solution phase diffusion mass transfer conditions. The $\Delta \mathrm{E}_{\mathrm{p}}$ values range from $0.0210 \mathrm{~V}$ to $0.485 \mathrm{~V}$ using scan rates between $0.100 \mathrm{~V} / \mathrm{sec}$ to $10.0 \mathrm{~V} / \mathrm{sec}$. The increase in peak separation with higher scan rates is attributed to kinetic limitations of charge transfer between redox sites within the polymer film. Scan rates lower than $0.020 \mathrm{~V} \cdot \mathrm{sec}^{-1}$ produced $\Delta \mathrm{E}_{\mathrm{p}} \sim 0 \mathrm{~V}$. This peak separation indicates facile charge transfer within the film and Nernstian equilibrium conditions of charge transfer with the applied potential. The peak width at half-height is greater than $90.6 \mathrm{mV}$ which indicates non-equivalent redox centers and/or repulsive or attractive forces within the film [Brown et. al 2002]. Worth mentioning is that when the film is in a fully reduced state, the film has a negative charge which must be compensated by a counterion entering the film, (i.e., $\left.\mathrm{N}\left(\mathrm{CH}_{3} \mathrm{CH}_{2}\right)_{4}{ }^{+}\right)$, in order to maintain charge electroneutrality. Due to solvent-ion interactions, the entering counterion is accompanied by solvent sphere(s). This may result in possible polymeric film swelling. Diagnostic plots of the anodic and cathodic peak current versus the scan rate from $1.600 \mathrm{~V}$ to $0.400 \mathrm{~V}$ for the thin films were linear for scan rates $<$ $1 \mathrm{~V} / \mathrm{sec}$. Using scan rates $<1 \mathrm{~V} / \mathrm{sec}$ allowed for finite diffusion boundary conditions to dominate the electrochemical charge transfer process. However, plots of the peak current versus the square root of the scan rate were linear for scan rates $>1 \mathrm{~V} / \mathrm{sec}$, indicating semi-infinite diffusion conditions. Under the latter conditions, it is possible that not all the redox sites are reduced and oxidized during the voltammetric scan. In this case, the charge transfer models the Randles-Sevcik equation:

$$
I_{p}=\left(2.69 \times 10^{5}\right) \mathrm{n}^{3 / 2} \mathrm{AD}^{1 / 2} \mathrm{v}^{1 / 2} \mathrm{C}
$$

where $D$ represents the apparent charge transfer coefficient and $C$ represents the concentration of oxidized or reduced ruthenium sites within the film. The other symbols have their normal electrochemical convention. In addition, at higher scan rates, the depletion layer above the surface of the electrode is thinner than the film thickness, and hence the system resembles semi-infinite diffusional boundary conditions (Collins 1996). 


\subsubsection{Surface Coverage}

Surface coverage of the electrode was determined using the equation: $\Gamma=Q / n F A$, where $\Gamma$ is the surface coverage in $\mathrm{mol} / \mathrm{cm}^{2}, Q$ is the charge in coulombs, $A$ is the area of the electrode surface in $\mathrm{cm}^{2}$, and $n$ is the number of electrons transferred during redox transformation. The value of $Q$ was determined by integrating the area under the cathodic peak or anodic peak during the characterization of the electrode in the supporting electrolyte solution. The surface coverage was determined using anodic peak, corresponding to the $\mathrm{Ru}^{2+} \rightarrow \mathrm{Ru}^{3+}$ $+\mathrm{e}^{-}$process. Figure 5 shows the surface coverage with respect to the number of cycles of electropolymerization. Surface coverage ranges from $9.42 \times 10^{-11} \mathrm{~mol} / \mathrm{cm}^{2}$ to $4.76 \times 10^{-10} \mathrm{~mol} / \mathrm{cm}^{2}$, corresponding to $30-90$ cycles of electropolymerization. In addition, Figure 5 shows a leveling-effect corresponding to approximately 90 cycles of electropolymerization, correlating with the time needed to reach a steady-state peak current during the electropolymerization process.

\section{Conclusion}

Compared to other electrode modification procedures, the preparation of these films by electropolymerization using cyclic voltammetry is relatively simple in design, and is a one-step process. Building into the monomer an organic moiety such as a vinyl substituent allows for successful electropolymerization reactions to occur. The thin films exhibit facile electron transfer properties in propylene carbonate/TEAP supporting electrolyte solutions. For example, characterization scan rates near $1.000 \mathrm{~V} / \mathrm{sec}$ produced peak separations under $0.100 \mathrm{~V}$. At low scan rates, the peak separations are practically $0 \mathrm{mV}$. However, metal-based modified electrodes have peak separations of approximately $0.700 \mathrm{~V}$ at $1.000 \mathrm{~V} / \mathrm{sec}$ (Razmi-Zerbin et. al 2002). The films presented herein require about 30 minutes to prepare and are now being investigated for long-term stability for potential use in flow injection analysis in the determination of hydrazine.

\section{References}

Abruna, H.D., Denisevich, P., Umana, M., Meyer, T.J., and Murray, R.W. (1981). Rectifiying interfaces using two-layer films of electrochemically polymerized vinylpyridine and vinylbipyridine complexes of ruthenium and iron on electrodes. J. Am. Chem. Soc, 103, 1-5.

Allen, J.R., Florido, A., Young, S.D., Daunert, S., and Bachus, L.G. (1995). Nitrite-selective electrode based on an electropolymerized cobalt phthalocyanine. Electroanalysis, 7, 710-713.

Bobacka, J., Gao, Z., Ivaska, A., and Lewenstam, A. (1994). Mechanism of ionic and redox sensitivity of p-type conducting polymers: Part 2. Experimental study of polypyrrole, 368, 33-41.

Brown, K. and Mottola, H. (1998). Voltammetric, chronocoulometric and spectroelectrochemical studies of electropolymerized films based on $\mathrm{Cu}(\mathrm{II} / \mathrm{I})-4,9,16,23$-tetraaminophthalocyanine. Langmuir, 14, 3411-3417.

Brown, K., Shaw, J., Ambrose, M., and Mottola, H. (2002). Voltammetric, chronocoulometric and spectroelectrochemical studies of electropolymerized films based on $\mathrm{Co}(\mathrm{III} / \mathrm{II})-$ and $\mathrm{Zn}$ (II) 4,9,16,23-tetraaminophthalocyanine: effect of high pH. Microchemical Journal, 72, 285-298.

Calvert, J.M., Schemehl, R.H., Sullivan, B.P., Facci, J.S., T.J. Meyer, and R.W.Murray, (1983). Synthetic and mechanistic investigations of the reductive electrochemical polymerization of vinyl-containing complexes of iron(II), ruthenium(II), and osmium(II). Inorg. Chem., 22, 2151-2162.

Collins, Greg. E. (1996). Gas-Phase chemical sensing using electrochemiluminscence. Sensors and Actuators B, 35-36, 202-206.

Green, M.J., Faulkner, L.R. (1983). Reversible Oxidation and Rereduction of Entire Films of Transition-Metal Phthalocyanines. J. Am. Chem. Soc., 105, 2950-2955.

Guarr, T.F. and Anson F.C. (1987). Electropolymerization of Bis(1,10-phenanthroline) (4-methyl-4'-vinyl-2,2'-bipyridine) complexes through direct attack on the ligand ring system. J. Phys. Chem., 91: 4037-4043.

Hurrell, H.C., Mogstad, A.L., Usifer, D.A., Potts, K.T., and Abruna, H.D. (1989). Electrocatalytic activity of electropolymerized films of Bis(vinylterpyridine)cobalt(2+) for the reduction of carbon dioxide and oxygen. Inorganic Chemistry, 28, 1080-1084.

Kang, T.F., Xie, Z.-Y., Tang, H., Shen, G.-L., and Yu, R.-Q. (1997). Potentiometric pH sensors based on chemically modified electrodes with electropoylymerized metal-tetraminophthalocyanine. Talanta, 47, 291-296.

Lane, R.F., and Hubbard, A.T. (1973). Electrochemistry of Chemisorbed Molecules. I. Reactants Connected to Electrodes through Olefinic Substituents. J. Phys. Chem., 77, 11, 1401-1410. 
Li, H., and Guarr, T.F. (1991). Electrocatalytic oxidation of oxalic acid at electrodes coated with polymeric metallophthalocyanines. J. Electroanal. Chem., 371, 189-202.

Pinter, J.S., Brown, K.L., DeYoung, P.A., and Peaslee, G.F. (2007). Amperometric detection of hydrazine by cyclic volammetry and flow injection analysis using ruthenium modified glassy carbon electrodes. Talanta, 71, 1219-1225.

Razmi-Nerbin, H. and Rournaghi-Azar, M.H. (2002). Nickel pentacyanonitrosylferrate film modified aluminum electrode for electrocatalytic oxidation of hydrazine. J. Solid State Electrochem, 6, 126-133.

Wang, J. (1996). Electrocatalytic reduction and flow injection analysis of organic peroxides at polymeric tetra-amino iron phthalocyanine modified electrode. Analytical Letters, 29(9), 1575-1587.

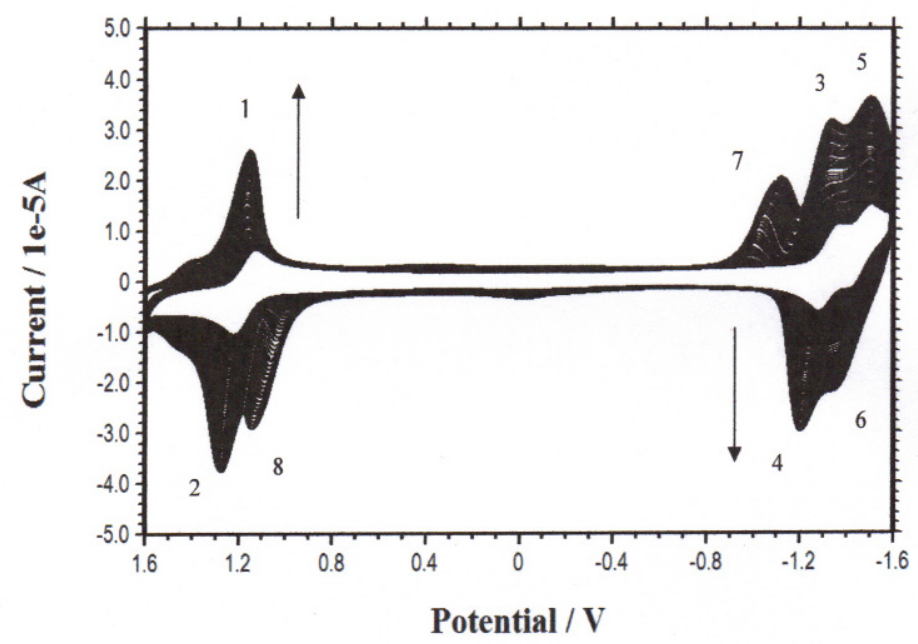

Figure 1. Electropolymerization of $\left.1.00 \times 10^{-3} \mathrm{M} \mathrm{Ru(II)-(phen)}\right)_{2}$ vbpy. Supporting electrolyte is $0.100 \mathrm{M}$ TEAP and solvent is propylene carbonate. Scan Rate $=0.100 \mathrm{~V} / \mathrm{sec}$. Seventy cycles of electropolymerization from $1.600 \mathrm{~V}$ to $-1.600 \mathrm{~V}$ vs. $\mathrm{Ag} / \mathrm{AgCl}$ 


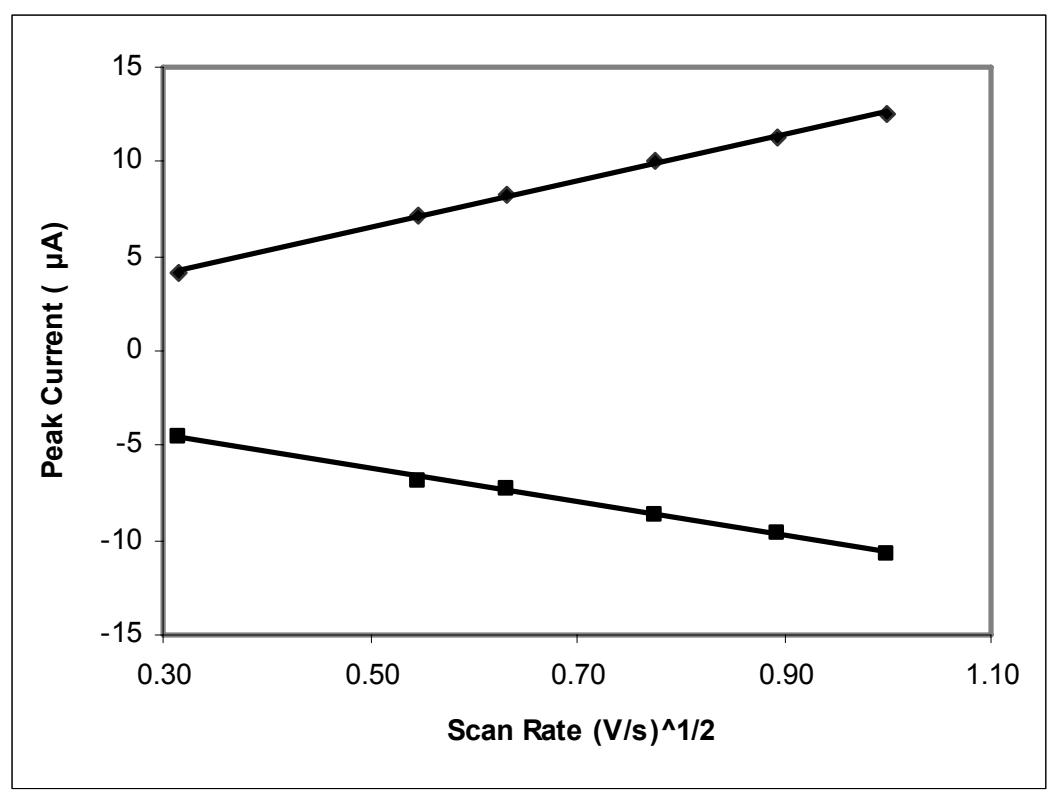

Figure 2. Plots of cathodic and anodic peak currents at various scan rates during electropolymerization of the ruthenium complex $\left(1.00 \times 10^{-3} \mathrm{M} \mathrm{Ru}(\mathrm{II}) \text {-(phen }\right)_{2} \mathrm{vbpy}$ in $0.10 \mathrm{M}$ TEAP in propylene carbonate). Scan rates: $0.100 \mathrm{~V} / \mathrm{sec}-1.00 \mathrm{~V} / \mathrm{sec}$. Peak currents taken during the third cycle of electropolymerization corresponding to the $\mathrm{Ru}(\mathrm{III} / \mathrm{II})$ redox couple

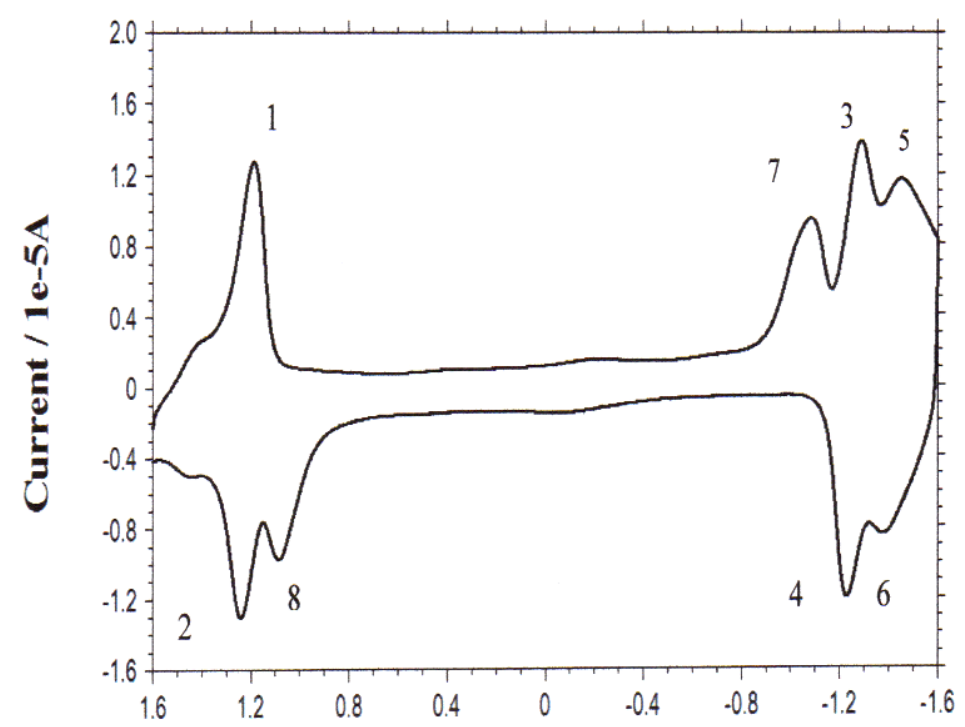

Potential / V

Figure 3. Characterization of ruthenium film in $0.100 \mathrm{M}$ TEAP in propylene carbonate at $0.100 \mathrm{~V} / \mathrm{sec}$ from 1.600 $\mathrm{V}$ to $-1.600 \mathrm{~V}$ vs. $\mathrm{Ag} / \mathrm{AgCl}$ 


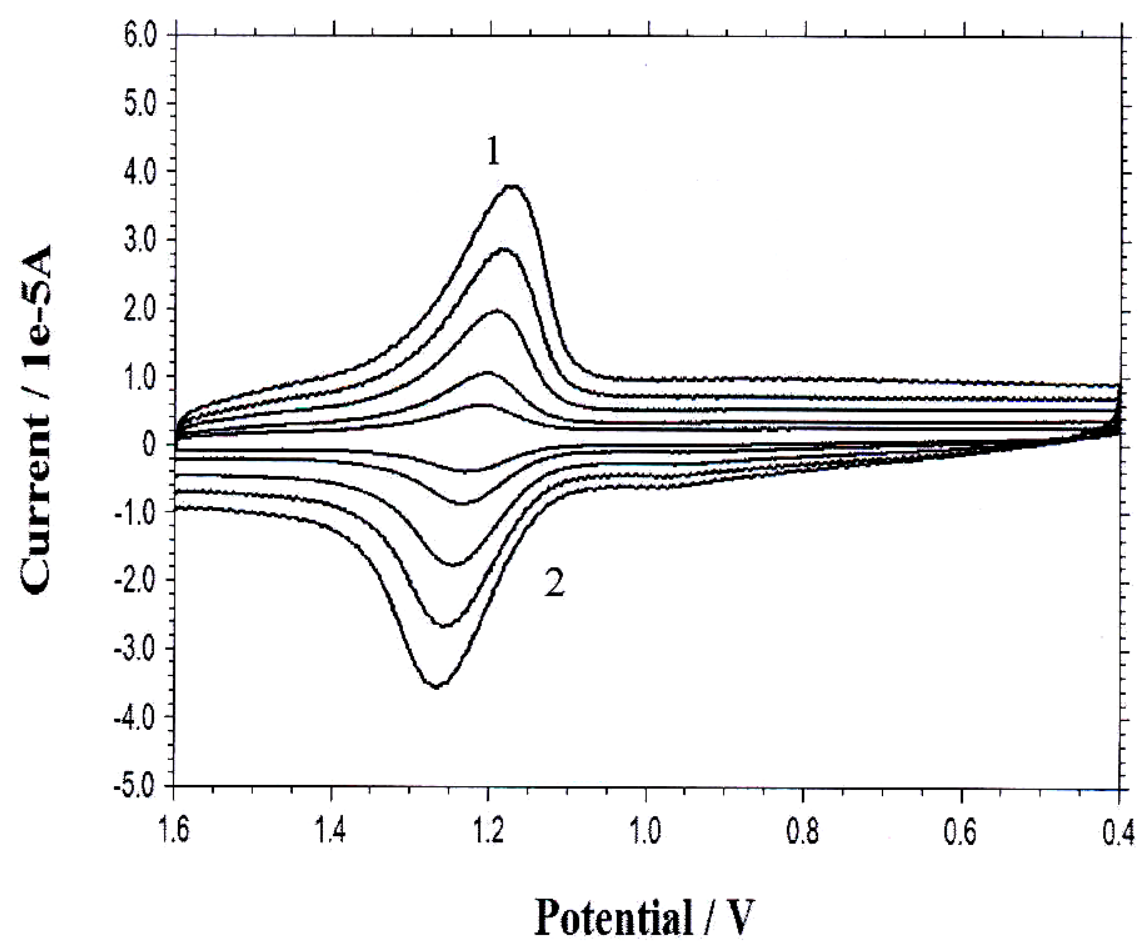

Figure 4. Characterization of ruthenium film in $0.100 \mathrm{M}$ TEAP in propylene carbonate at $0.100 \mathrm{~V} / \mathrm{sec}-1.00$ $\mathrm{V} / \mathrm{sec}$ from $1.600 \mathrm{~V}$ to $0.400 \mathrm{~V}$ based on the $\mathrm{Ru}(\mathrm{III} / \mathrm{II})$ redox couple

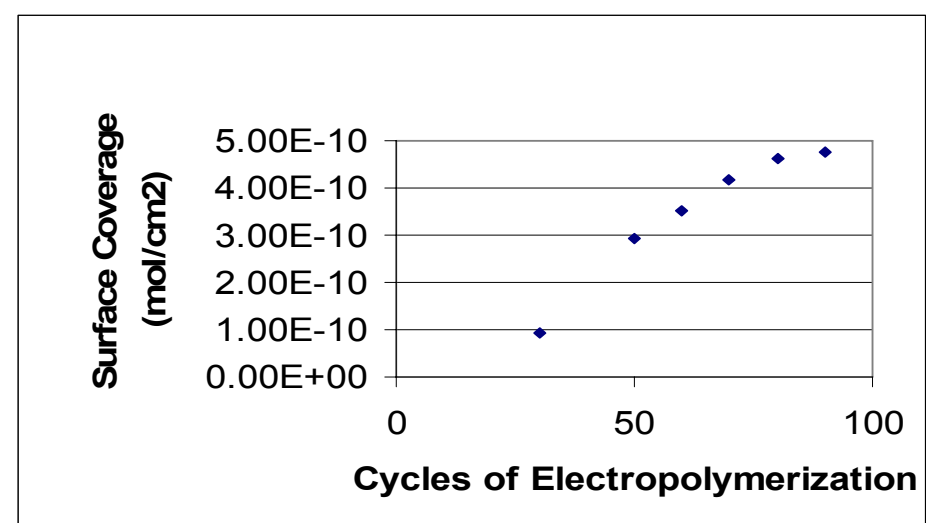

Figure 5. Profile of surface coverage with the number of electropolymerization cycles. Data taken from the characterization of the film corresponding to $\mathrm{Ru}^{2+} \rightarrow \mathrm{Ru}^{3+}+\mathrm{e}^{-}$anodic peak in $0.10 \mathrm{M}$ TEAP in propylene carbonate 